\title{
Item Context Effects in IS Survey Research
}

\author{
Wendy Hui \\ School of Information Systems \\ Curtin University \\ Perth, Australia \\ wendy.hui@curtin.edu.au
}

\begin{abstract}
This paper discusses correlational and directional item context effects as two method biases that can threaten the validity of survey data. Two empirical studies are used to establish their presence in IS research. In addition, item separation with partial randomization is shown to be a viable way for researchers to control for correlational item context effects associated with inflated Cronbach's alphas. This paper also presents a procedure to correct the inter-construct correlations and $R^{2}$ values to account for directional item context effects in comparative experimental studies.
\end{abstract}

Keywords: Questionnaire surveys, Research methods, Item context effects 


\section{Introduction}

Behavioral researchers in Information Systems (IS) often rely on self-reports to investigate user perceptions, attitudes and intentions related to Information Technology (IT). However, the literature suggests that self-reports are subject to various method biases, including social desirability, common method variance, consistency motif and implicit theories, among others (Podsakoff et al., 2003). These biases may systematically inflate or deflate correlations between question items and constructs, and thus may affect the validity of statistical inferences. Although method biases can affect the validity of research findings, they have not received much discussion in the IS literature until recently (e.g., Malhotra, 2006; King et al., 2007; Burton-Jones, 2009; Sharma et al., 2009).

Studies in applied psychology, organizational behavior and marketing have assessed method biases and have arrived at different conclusions about the size of their effects (e.g., Cote and Buckley, 1987; Spector, 1987; Doty and Glick, 1998). To reconcile these findings, Crampton and Wagner (1994) called for continued "domain specific" research to identify areas that are most susceptible to method biases. In IS, common method variance has generated the most research attention among other method biases (e.g., Malhotra, 2006; Sharma et al., 2009). However, as pointed out by Burton-Jones (2009), common method variance is only one of many method biases associated with self-reports. This paper focuses on item context effects, which refer to any influence or interpretation that a respondent might ascribe to a question item because of its relation to the other items making up an instrument or survey ${ }^{1}$ (Wainer and Kiely, 1987; Tou-

\footnotetext{
${ }^{1}$ In other words, response to an item can be affected by other items of the same construct in the survey as well as items of other constructs in the survey.
}

rangeau et al., 2000). These effects include item priming effects and intermixing (or grouping) of items or constructs in the questionnaire (Podsakoff et al., 2003). Item context effects differ from measurement context effects, which refer to the broader research context including the time, location and media used for construct measurements (Podsakoff et al., 2003). This paper focuses on item context effects, i.e., how items in a survey may create a context that affects the response to other items in the survey.

According to Tourangeau and Rasinski (1988), questions about unfamiliar issues, inaccessible attitudes, mixed or conflicted beliefs and related judgment items tend to increase the susceptibility to inflated or deflated item correlations, while knowledge, involvement and the allowance of sufficient time for survey response help reduce item context effects. Many survey studies in IS ask subjects about systems with which they do not have much experience (e.g., adoption of new technologies). In some studies, the researchers provide some prior training or a brief introduction to the new technology before the survey is conducted (e.g., Davis et al., 1989). However, it is unlikely that the respondents can acquire a solid understanding of the technology within a short time frame. Therefore, compared to other management research that involves employees' assessment of their job, supervisor or organization, which they are already familiar with, or social science research that involves a person's opinion about a government policy which affects them directly and hence represents a high-involvement issue, IS survey research may be more susceptible to item context effects.

According to Tourangeau et al.'s (2000), there are two types of item context effects. Correlational item context effects can inflate or deflate correlations between items or constructs; whereas directional item context effects can shift the mean value of an item or construct. 
Based on this classification, this paper identifies three possible ways in which item context effects can threaten data validity. Firstly, correlational context effects may inflate intraconstruct correlations and produce exaggerated construct reliability statistics. Secondly, correlational item context effects can inflate or deflate interconstruct correlations. An inflated interconstruct correlation inflates the path significance in a structural equation model, which in turn increases the likelihood of falsely rejecting the null hypothesis or accepting a poor theory. Thirdly, the questions in a survey may prime respondents to consistently answer subsequent attitude questions more or less favorably. These priming effects can shift the mean value of the construct measurements, resulting in directional item context effects (Tourangeau et al., 2000, p. 198). As we shall discuss in the following sections, the presence of directional item context effects may make it difficult to compare different models, which is a common exercise when researchers wish to critically assess competing theories (e.g., Davis et al., 1989; Mathieson, 1991, Taylor and Todd, 1995; Gobet, 1998; Hsiao and Oxford, 2002; Kingston and Caballero, 2009).

This paper seeks to contribute to the IS literature by increasing the awareness of item context effects among IS researchers and discussing various ways to minimize their effects. Specifically, the objectives of this paper are: (1) to empirically show the presence of these three types of survey biases in the IS context, (2) discuss various methods suggested by the literature to minimize their effects, (3) establish item and construct separation as a viable, cost-effective way to reduce correlational context effects, and (4) propose a new statistical remedy to remove directional item context effects relative to a reference context; this method is useful in comparative experimental studies involving surveys.
The rest of the paper is organized as follows. Firstly, the relevant literature is reviewed, in order to establish the theoretical basis of our research design and data analysis. Then, two empirical studies are presented to highlight correlational and directional item context effects in IS and to discuss their research implications. Next, methodological remedies are discussed. Finally, we conclude the paper and identify future research directions.

\section{Literature Review}

Theories of human behavior often seek to explain the relationships between variables that reside within an individual's mind, e.g., emotion, perception, attitude and intention. In order to empirically validate such theories, researchers typically measure these variables using selfreported data collected through surveys. Although some issues inherent in the survey method are yet to be resolved (Edwards, 2008), recent developments in social measurement have provided useful guidelines for researchers to minimize various survey method biases. For example, based on cognitive models, studies in the cognitive aspects of survey methodology (CASM) have deepened our understanding of the cognitive processes underlying survey method biases, identified survey structures and questions that are likely to be error-prone, and shown how cognitively burdensome questions can be detected and corrected (Schwarz, 1999; Tourangeau et al., 2000).

Feldman and Lynch's (1988) accessibility-diagnosticity model is a cognitive model in CASM that can be used to explain item context effects. According to this model, accessibility refers to the ease with which an input in memory is brought to mind, whereas the diagnosticity of an input in the memory refers to the degree to which an individual believes that the decision implied by that input alone would accomplish his or her decision goals (Lynch, 2005). Feldman and 
Item Context Effects in IS Survey Research / Hui

Lynch (1988) note that very often in a survey context, constructs of interest to the researcher do not exist in the memory of the respondent before questions are asked. Answers to earlier questions about a construct can increase the construct's accessibility in the memory, making it more likely to be used to compute answers to later questions in the survey.

The accessibility-diagnosticity model does not stipulate exactly how question items in a survey affect each other. Tourangeau et al. (2000) identify two types of correlational item context effects: Assimilation effects arise when survey contexts inflate the correlations, whereas contrast effects occur when survey contexts reduce the correlations. Study 1 of this paper illustrates assimilation effects. However, regardless of the type of correlational item context effects, the difference between the "true" correlation and the observed correlation is attributable to the disproportionate weights assigned to previously answered items that linger in the working memory. The techniques used to minimize assimilation effects can often be used to minimize contrast effects as well.

Directional item context effects are closely related to unconditional context effects (Tourangeau et al., 2000, p. 198), where context items have the same impact on target items (i.e., items affected by item context effects) regardless of how respondents answer the context items (i.e., items that create item context effects). Tourangeau et al. (1989a) suggest that context items make relevant concepts more accessible, and that these "primed" concepts may induce more or less favourable positions on the target issue in an automatic process unconscious to the respondent. This explains why directional item context effects need not depend on the responses to the context items. For example, in a study conducted by Tourangeau et al. (1989b), respondents were divided into three groups and were asked to answer different sets of questions about defense spending. One group was asked about military threats posed by the Soviet Union prior to being asked about defense spending, whereas the other groups were asked about the need for arms control and other unrelated questions. It was found that regardless of how questions on Soviet threats were answered, respondents in the first group showed significantly greater support for an increase in defense spending.

The literature provides a number of guidelines to minimize correlational item context effects. Podsakoff et al. (2003) suggest the use of measurement separation between related questions to minimize item context effects. Such separation could be psychological, temporal or geographical. One possible way to introduce a distance between questions belonging to the same construct is to separate items by spreading them across the questionnaire in a random order. If a questionnaire is long and complete randomization is expected to cause frustration to respondents, partial randomization can be adopted, as shown in Study 1. In the same vein, construct separation can alleviate the problem of inflated interconstruct correlations. Podsakoff et al. (2003) also discuss a number of other measurement separation techniques, including the use of different response formats and data collection media for construct measurements. They are not presented here in the interest of space.

For directional item context effects, a simple solution to improve the performance of predictive models of behavior is to apply appropriate discounting factors to the predictions (Chandon et al., 2005). Chandon et al. (2005) also develop a latent model to account for the effects of survey measurement. Ostroff et al. (2002) show that the individual level method bias can result in aggregate level bias, and suggest the use of a splitsample design to conduct cross-level and multilevel studies. This idea can be ap- 
plied to research on technology adoption. For example, if multiple technologies are investigated and if system characteristics are identified to be variables that may cause priming effects, multilevel analysis can be conducted at both the individual and technology levels. Technology level variables can be aggregated from one group of respondents, while the individual-level variables are obtained from another group of respondents. In this way, the split-sample design prevents the measurement of system characteristics to affect the measurement of individual beliefs, attitudes and intentions. This approach, however, cannot be applied to studies that focus on a single technology.

In the following sections, we present two empirical studies that show the presence of correlational item context effects and directional item context effects in IS research. The use of item separation to reduce correlational item context effects is demonstrated and the viability of this approach is also discussed. As the literature does not provide a simple solution to deal with directional item context effects, we propose a new statistical remedy. In the Conclusion section, we explain the main limitation of the proposed remedy and how this limitation can be addressed using split questionnaire design (Raghunathan and Grizzle, 1995).

\section{Study 1 - Correlational Item Context Effects}

In this study, constructs from a research model are measured in two different ways to demonstrate empirically that correlational item context effects can affect data quality in IS survey research. A model from the area of information security is chosen because many of the research models in the area require respondents to assess risks associated with security breaches (e.g., $\mathrm{Ng}$ et al., 2009; Herath and Rao, 2009; Bulgurcu et al., 2010); yet, humans are in general not very good at assessing risks (Slovic, 1987 ) and their risk assessment is often affected by availability bias (Tversky and Kahneman, 1974). Thus, survey contexts can unexpectedly make certain concepts more salient, influencing the respondents' risk assessment and as a result impacting the validity of the survey data.

Podsakoff et al. (2003) suggest that separation of measurement can be used to reduce the effects of correlational item context effects. When a study is susceptible to correlational item context effects, correlations between the items of the same construct are expected to be greater when the items are measured without separation then when they are measured with separation. Since Cronbach's alpha is directly related to correlations between items of a construct, we test the presence of correlational item context effects by testing the following hypothesis:

H1: The Cronbach's alpha values of constructs measured without item separation are bigger than those measured with item separation.

\section{Research Design}

Our survey involves six latent variables from $\mathrm{Ng}$ et al. (2009) that are perceptions measured by self-reports. They are Perceived Susceptibility (SUS), Perceived Severity (SEV), Perceived Benefits (BEN), Perceived Barriers (BAR), SelfEfficacy (SEF) and General Security Orientation (GEN). Organizational factors in $\mathrm{Ng}$ et al. (2009) were not included because they were not relevant to our target population. In order to come up with a balanced design, each construct was measured using four items; where a construct had fewer than four items, more items were developed and added to the survey, as indicated in Appendix A. It is important to note that it is NOT the aim of this paper to evaluate the theory in $\mathrm{Ng}$ et al. (2009). In fact, the dependent variable of the model was not measured in our survey. We chose $\mathrm{Ng}$ et al. (2009) mainly because of its appropriate model size for our purpose and its survey context in in- 
Item Context Effects in IS Survey Research / Hui

formation security, which makes it likely to be susceptible to item context effects as discussed earlier.

Study 1 employed a $2 \times 1$ experimental design. One group answered a questionnaire that presents items grouped by constructs, i.e., items measuring the same construct were placed next to each other. The second group answered a survey with items arranged in blocks of six. Within each block, there was one item from each of the six constructs being measured. The items within each block were arranged in a random order, so that subjects could not identify a fixed pattern in the blocks and be tempted to answer questions without reading them carefully. The online survey website presented 12 questions per page. Figure 1 presents the order of question items in both groups.

For short surveys, it may be fine to use complete randomisation without arranging the items in blocks. However, if the survey is long, this may increase survey fatigue in the respondents. Arranging items in blocks of reasonable sizes can ensure that respondents do not need to deal with too many concepts at the same time. According to Miller (1956), human working memory typically can deal with 7 \pm 2 elements at the same time. Therefore, a block size of about seven is likely to reduce item context effects without creating a heavy cognitive burden on the respondents.

The time required to complete the questions on pages 1 and 2 was recorded. Towards the end of the survey, both groups were also asked to evaluate their survey response experience. These questions are: (1) "Overall, the survey was easy to complete", (2) "I enjoyed completing the survey" and (3) "Overall, I am satisfied with the survey".

\section{Data Collection}

The subjects involved in this study were students from the China campus of a major university on the UK. The China campus currently has over 4,800 students from dozens of countries around the world. A total of 667 first year students from a compulsory introductory IT course were randomly selected and invited to take part in the study at the beginning of the Spring semester of 2011. Participants were alternately assigned to one of two experimental groups based on their order of participation (i.e., when they visited the online survey web page). The first participant was assigned to Group 1, the second to Group 2, the third to Group 1, the fourth to Group 2, and so on. This type of assignment involves systematic sampling (Fowler, 2009, p. 25). Since participation was not ordered in any meaningful way, the result of the assignment is equivalent to random assignment. Hence, subjects in Group 1 and Group 2 should be equivalent in terms of their demographics.

Student participation was not compulsory but as a reward to encourage participation, those who took part in the survey would have their print accounts increased by an amount equivalent to 500 A4-sized pages. The survey was made available for one week. 169 and 168 usable records were collected for Group 1 and Group 2 respectively, representing a response rate of $50.5 \%$.

\section{Data Analysis}

\section{Effects of Item Randomization on Construct Reliability}

Table 1 presents the Cronbach's alpha

\begin{tabular}{|l|c|c|}
\hline & Group 1 & Group 2 \\
\hline \multirow{2}{*}{ Page 1 } & $\begin{array}{c}\text { SUS1, SUS2, SUS3, SUS4, SEV1, SEV2, } \\
\text { SEV3, SEV4, BEN1, BEN2, BEN3, BEN4 }\end{array}$ & $\begin{array}{c}\text { BAR1, SUS1, GEN1, SEF1, SEV1, BEN1, } \\
\text { GEN2, SEF2, SEV2, SUS2, BEN2, BAR2 }\end{array}$ \\
\hline \multirow{2}{*}{ Page 2 } & $\begin{array}{l}\text { BAR1, BAR2, BAR3, BAR4, SEF1, SEF2, } \\
\text { SEF3, SEF4, GEN1, GEN2, GEN3, GEN4 }\end{array}$ & SEF3, SEV3, GEN3, BEN3, SUS3, BAR3, \\
BEN4, SEF4, GEN4, SEV4, BAR4, SUS4 \\
\hline
\end{tabular}




\begin{tabular}{|c|c|c|c|}
\hline & $\begin{array}{c}\text { Group } 1 \\
\text { (No Item } \\
\text { Separation) } \\
(n=168)\end{array}$ & $\begin{array}{c}\text { Group } 2 \\
\text { (Item } \\
\text { Separation) } \\
(n=169)\end{array}$ & $\begin{array}{l}\text { Significance } \\
\left(H_{0}: \alpha_{1}=\alpha_{2}\right)\end{array}$ \\
\hline Perceived Susceptibility (SUS) & 0.8131 & 0.7339 & $0.0114^{*}$ \\
\hline Perceived Severity (SEV) & 0.7940 & 0.6378 & $0.0001^{* * *}$ \\
\hline Perceived Benefits (BEN) & 0.8346 & 0.7551 & $0.0057^{* *}$ \\
\hline Perceived Barriers (BAR) & 0.7281 & 0.6066 & $0.0087^{* *}$ \\
\hline Self-Efficacy (SEF) & 0.8960 & 0.8551 & $0.0163^{*}$ \\
\hline General Security Orientation (GEN) & 0.7382 & 0.6053 & $0.0041^{* \star}$ \\
\hline
\end{tabular}

* Significant at the 0.05 level. ${ }^{* *}$ Significant at the 0.01 level. ${ }^{* * *}$ Significant at the 0.001 level.

values of the measured constructs for both groups. As shown, all Cronbach's alpha values are greater than 0.6 , suggesting that the instruments are reasonably reliable. The purpose of Study 1 , however, is to show that the Cronbach's alpha values decrease significantly in a design with item separation compared to a design without item separation. Thus, if an instrument had not been properly developed, a questionnaire design without item separation might not be able to detect items that should have be dropped.

The Feldt test (Feldt, 1969) was used to test whether or not the Cronbach's alphas from the two questionnaire designs are statistically different. Table 1 presents the test results, where $\alpha$ denotes the Cronbach's alpha value and the subscript denotes the experimental group. As shown, the Cronbach's alpha values associated with item separation are smaller than those associated with no item separation. All differences are statistically significant at the 0.05 level, suggesting that item context effects can inflate Cronbach's alphas.

\section{Further Analysis}

According to the accessibilitydiagnosticity model, when a construct is conceptually related to other constructs in the theory, responses to questions about the construct can be used to compute responses to questions about the other constructs, resulting in inflated interconstruct correlations. Although Study 1 was specially designed to study the problem of inflated Cronbach's alphas, the design described in Figure 1 allows us to investigate whether measurement separation can be used to reduce the problem of inflated interconstruct correlations as well. We note that subjects in Group 1 answered questions related to SUS, SEV and BEN and questions related to BAR, SEF and GEN on different pages, while subjects in Group 2 answered questions about all constructs on each page. If measurement separation decreases interconstruct correlations, we should expect to see that, overall, the correlations between constructs presented on the first page (SUS, SEV and BEN) and constructs presented on the second page (BAR, SEF and GEN) to be larger in Group 1 than those between the corresponding constructs in Group 2 due to further distance between constructs as well as the psychological gap introduced by the page separation. Table 2 presents the interconstruct correlation matrix for each group ${ }^{2}$.

The shaded cells represent correlations of constructs that are presented in

\footnotetext{
${ }^{2}$ To avoid unequal disattenuation of correlations between the two groups (Bedeian et al., 1997), the average item score for each construct has been used to calculate the correlations.
} 
Table 2 - Interconstruct Correlation Matrices for Experimental Groups

Group 1 (Construct Separation between SUS, SEV, BEN and BAR, SEF, GEN)

\begin{tabular}{|c|c|c|c|c|c|c|}
\hline & SUS & SEV & BEN & BAR & SEF & GEN \\
\hline SUS & 1 & & & & & \\
\hline SEV & 0.3627 & 1 & & & & \\
\hline BEN & 0.1347 & 0.5022 & 1 & & & \\
\hline BAR & 0.1522 & 0.2833 & 0.1049 & 1 & & \\
\hline SEF & 0.2007 & 0.0137 & 0.1465 & 0.1174 & 1 & \\
\hline GEN & 0.1570 & 0.0350 & 0.2131 & 0.0757 & 0.3543 & 1 \\
\hline \multicolumn{7}{|c|}{ Group 2 (No Construct Separation between SUS, SEV, BEN and BAR, SEF, GEN) } \\
\hline & SUS & SEV & BEN & BAR & SEF & GEN \\
\hline SUS & 1 & & & & & \\
\hline SEV & 0.3039 & 1 & & & & \\
\hline BEN & 0.1184 & 0.3727 & 1 & & & \\
\hline BAR & 0.2491 & 0.2883 & 0.2810 & 1 & & \\
\hline SEF & 0.0843 & 0.1634 & 0.3395 & 0.1788 & 1 & \\
\hline GEN & 0.1861 & 0.4157 & 0.4625 & 0.1428 & 0.4355 & 1 \\
\hline
\end{tabular}

\begin{tabular}{|l|c|c|c|c|c|c|}
\hline Table 3 - Assessing Respondents' Survey Experience \\
\hline & \multicolumn{2}{|c|}{ Group 1 } & \multicolumn{2}{c|}{ Group 2 } & Significance \\
\hline & Mean & S. D. & Mean & S.D. & $\left(H_{0}: \mu_{1}=\mu_{2}\right)$ \\
\hline $\begin{array}{l}\text { Time required to complete the first two pages (se- } \\
\text { conds) }\end{array}$ & 337.3 & 169.6 & 333.1 & 182.6 & 0.827 \\
\hline "Overall, the survey was easy to complete." & 3.95 & 1.15 & 3.90 & 1.12 & 0.686 \\
\hline "I enjoyed completing the survey." & 3.94 & 1.08 & 3.84 & 1.15 & 0.397 \\
\hline "Overall, I am satisfied with the survey." & 4.50 & 0.97 & 4.61 & 1.04 & 0.330 \\
\hline
\end{tabular}

different pages in Group 1. We note that the average correlation of the shaded cells is smaller than that of the corresponding cells in Group 2. Therefore, it seems that construct separation tends to yield lower interconstruct correlations.

Steiger (1980) presents a procedure to test the difference between elements of dependent correlation matrices. Steiger (2003) shows that a similar procedure can be used to test the difference between elements in independent correlation matrices. Furthermore, Steiger (2003) makes available a mathematical program called WBCORR for the test; it is available for download from www.statpower.net. By entering the following hypothesis into the WBCORR program

$$
H_{0}:\left\{\begin{array}{l}
r_{1, S U S-B A R}=r_{2, S U S-B A R} \\
r_{1, S U S-S E F}=r_{2, S U S-S E F} \\
r_{1, S U S-G E N}=r_{2, S U S-G E N} \\
r_{1, S E V-B A R}=r_{2, S E V-B A R} \\
r_{1, S E V-S E F}=r_{2, S E V-S E F} \\
r_{1, S E V-G E N}=r_{2, S E V-G E N} \\
r_{1, B E N-B A R}=r_{2, B E N-B A R} \\
r_{1, B E N-S E F}=r_{2, B E N-S E F} \\
r_{1, B E N-G E N}=r_{2, B E N-G E N}
\end{array}\right.
$$

where $r_{i, x-y}$ refers to the correlation between variables $x$ and $y$ observed in Group $i$, we found that there is a significant difference $\left(x^{2}=22.32, p=0.0079\right)$. Hence, there is evidence that construct separation decreases interconstruct correlations. 


\section{Respondents' Survey Experience}

To assess whether item separation with partial randomization has a negative impact on the respondents survey experience, we compared the between-group difference in terms of the required time to complete the first two pages of the survey (see Figure 1) and the self-reported survey experience. The relevant statistics are presented in Table 3.

Table 3 shows that there is no significant between-group difference in terms of the time required to complete the first two pages of the survey, although the standard deviation for the group with item separation seems to be slightly larger than the other group. Furthermore, respondents from both groups did not appear to differ in terms of their perceived ease of completing the survey and their overall satisfaction with the survey. These findings suggest that item separation with partial randomization is unlikely to create a heavy cognitive burden on the respondents or a significant reduction in response rate.

\section{Summary and Discussion}

Study 1 shows that intraconstruct and interconstruct correlations can be inflated if a questionnaire is not designed carefully. Inflated interconstruct correlations tend to inflate path coefficients and increase the likelihood of falsely rejecting the null hypothesis, and thus accepting a poor theory. Inflated intraconstruct correlations, on the other hand, tend to inflate construct reliability statistics, preventing the researcher from detecting unreliable data in the measurement model. Furthermore, in structural equation models, less reliable measurements actually receive a greater level of disattenuation when measurement errors are corrected, resulting in inflated path estimates (Bedeian et al., 1997).

Most established instruments in IS have been developed with methodological rigor (e.g., the Technology Acceptance
Model (TAM) by Davis, 1989)) and tested extensively under a wide variety of research settings using different questionnaire formats (e.g., Davis and Venkatesh, 1996). In such a way, researchers can accept their reliability and validity with confidence. However, newly developed instruments have not been subjected to such widespread scrutiny. In addition to following the existing guidelines for instrument development (e.g., DeVellis, 2003), researchers may consider using item separation to alleviate correlational item context effects. As shown in this study, this approach is simple and is unlikely to increase the cognitive burden for survey respondents.

An issue that has not been addressed in this study is the relative importance of intraconstruct correlations vs. interconstruct correlations. Sometimes, it is not possible to have both separation of question items within a construct and separation of question items between constructs. Further work is required to provide guidelines on determining which type of correlational item context effects is a greater threat given a research setting and thus should receive greater attention in the design of the questionnaire.

\section{Study 2 - Directional Item Context Effects}

Study 2 is a simple experiment aiming to illustrate how the measurement operation can affect survey respondents' attitudes towards a subject. It shows that the mean value of a measurement may be affected by other measurements made in the survey. Figure 2 shows the two models that are tested. TAM2 is an extension of the original TAM (Venkatesh and Davis, 2000), while Protection Motivation Theory (PMT) is a model that explains an individual's adaptive and maladaptive coping behaviors associated with a threat (Rogers, 1975). As the theory may not be familiar to the reader, a brief description is provided here. For further details, 
Item Context Effects in IS Survey Research / Hui

please refer to Rogers and PrenticeDunn (1997).

The original PMT models protection motivation as a function of perceived severity, perceived vulnerability and response efficacy (Rogers, 1975). Perceived severity refers to the consequence of a threat event, perceived vulnerability the probability of its occurrence, and response efficacy the effectiveness of the proposed protective measure. Using the threat of skin cancer as an example, a protective measure may be to wear a sun block on a sunny day. PMT suggests that an individual's intention to wear a sun block (protection motivation) is determined by the perceived consequences of skin cancer (perceived severity), the perceived probability of getting skin cancer (perceived vulnerability), and the perceived effectiveness of using a sun block to prevent skin cancer (response efficacy). In the context of security technology adoption, protection motivation is referred to as the intention to use the security technology, perceived severity as the perceived damage from a security incident, perceived vulnerability as the perceived likelihood of a security incident, and response efficacy as the effectiveness of the technology in minimizing the effects of a security incident.

It is hypothesized that asking respondents about their perceived severity and perceived vulnerability of a security threat may induce a greater intention to use a security technology, thus distorting the observed correlations between the intention to use and the other constructs in the model.

H2: Subjects exposed to question items in PMT show a higher intention to use a security technology than subjects exposed to question items in TAM2.

If support for this hypothesis is found, direct comparison between the two theoretical models in terms of variance explained becomes inappropriate because the survey respondents are no longer homogeneous, as we shall discuss shortly.

\section{Research Design}

In the middle of the Fall semester in 2009, 681 students from the same university taking the same introductory IT course

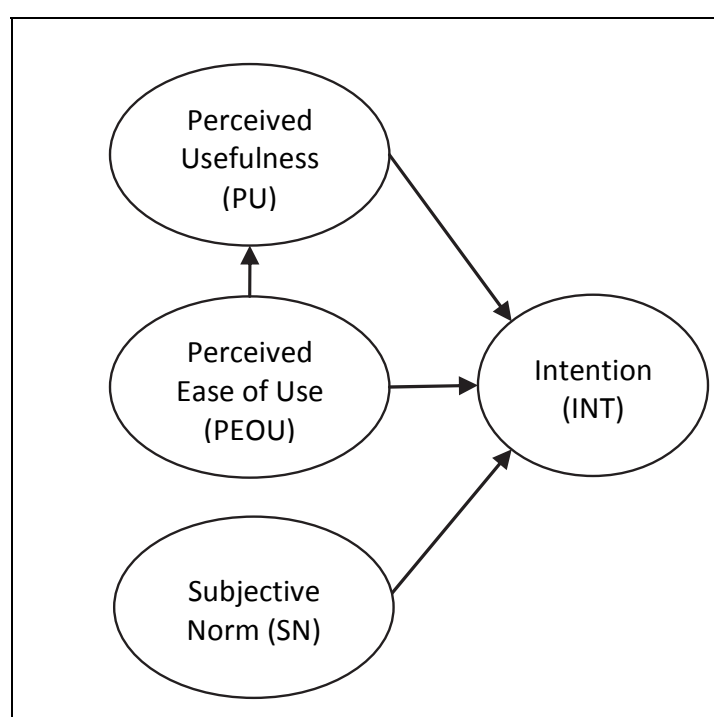

(a) TAM 2

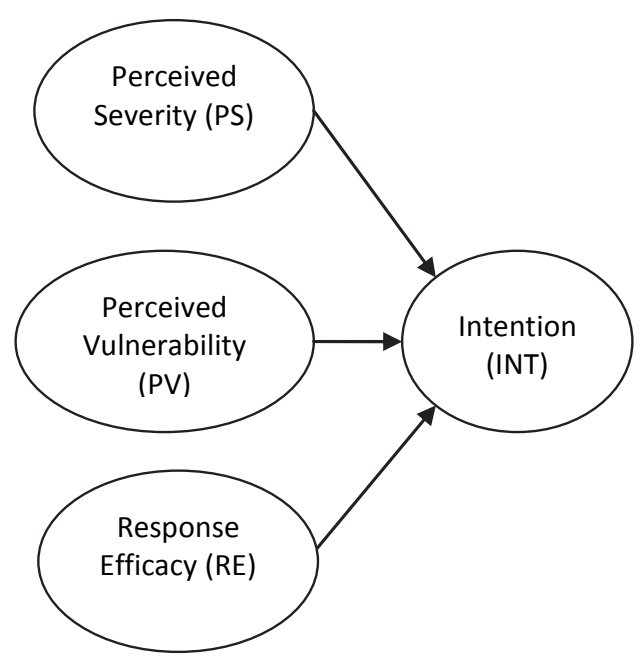

(b) PMT

Figure 2 - Research Model in Study 2 
were invited to participate in Study 2. The survey lasted for three days and student participation was motivated by offering them chances to win some stationery products. Participants were alternately assigned to one of two experimental groups based on their order of participation (i.e., when they visited the online survey web page). The first participant was assigned to Group 1, the second to Group 2, the third to Group 1, the fourth to Group 2, and so on. Since participation was not ordered in any meaningful way, the assignment yields the same result as random assignment. Hence, subjects from Group 1 and Group 2 should roughly be equivalent in terms of their demographics.

Group 1 answered randomized questions about constructs in a simple version of TAM2, whereas Group 2 answered randomized questions about constructs in $\mathrm{PMT}^{3}$. Intention to use was the common construct and was measured by the same question items in both groups. Subjects in both groups were asked to answer a total of 12 questions (Appendix C) that were rated on a 7-point Likert scale, with 1 = "strongly disagree" and 7 = "strongly agree." The technology examined was Hushmail, a web-based email service that protects email privacy using PGP encryption technology. Both groups were given a brief description of the purpose of the technology before they were presented with the survey questions.

\section{Data Analysis}

We received 176 and 171 completed records respectively from Group 1 and Group 2. Construct validity analyses (Appendix D) show that data from both groups exhibit satisfactory construct reliability, convergent validity and discrimi-

\footnotetext{
${ }^{3}$ As the survey was very short, there was no need to arrange the questions in blocks to reduce survey fatigue. Questions were completely randomized across the survey. However, the positions of the INT items in the questionnaire were the same in both groups.
}

nant validity. The path analysis results from SmartPLS 2.0 are presented in Figure 3 , which shows that the $R^{2}$ for INT in PMT is lower than that in TAM2. The results seem to suggest that PMT is a weaker theory. However, the mean INT in PMT (4.37) is higher than that in TAM2 (4.10), and the difference is statistically significant $(t=2.151, p=0.032)$. The effect size based on Hedges' $d$ is equal to 0.229 , with standard deviation $\sigma_{d}=0.108$ As explained earlier, systematic assignment guarantees that subjects in Group 1 and Group 2 are roughly equivalent in terms of their demographics. The difference in INT between the two groups is likely to be a result of the different items answered by the subjects. Because the question items change the subjects in the two groups differently, the path analysis results are not directly comparable.

\section{Summary and Discussion}

Study 2 empirically shows the presence of directional item context effects in an IS research context. These effects can hurt the accuracy of predictive models. For example, suppose PMT is used to investigate whether a new security technology will likely be accepted by potential users. Even with a representative sample, the measured intention will not accurately reflect the true intention of the target population. This is because, unlike the survey respondents, the target population has not been exposed to the PMT items. This problem is quite common in marketing research. One simple approach is to multiply the measured intention by an appropriate discounting factor (Chandon et al., 2005).

Another problem associated with directional item context effects relates to model comparison. In research that focuses on the testing of a standalone model, directional item context effects may not cause a practical concern as it is generally recognized that there is no single "perfect study" and that results from a single survey study may not be general 


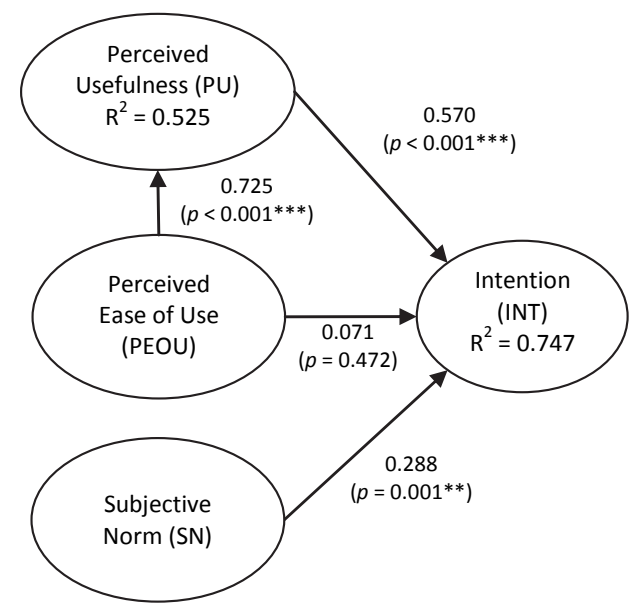

(a) TAM 2

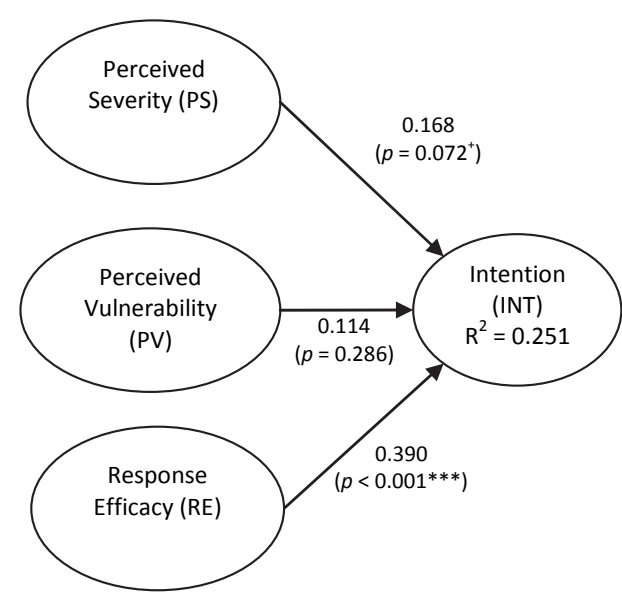

(b) PMT

${ }^{+}$Significant at the 0.1 level. * Significant at the 0.05 level. ${ }^{* *}$ Significant at the 0.01 level. ${ }^{* * *}$ Significant at the 0.001

\section{Figure 3 - Results for Path Analysis in Study 2}

izable to populations that are different from the sample (Hunter and Schmidt, 2004). Hence, replications in different research settings are important as they make available additional data in the literature for systematic review through qualitative narrative reviews and metaanalyses (Hunter and Schmidt, 2004), which are premised on the notion of shared subjectivity instead of true objectivity (DeCoster, 2004). Thus, having directional item context effects in a single survey study is like adding error to an already miscalibrated measurement; it may not seriously worsen the validity problem from a practical viewpoint. In experimental studies, one of the experimental groups is often used as a reference point for comparison and hence the measurements can be considered "calibrated". However, when different experimental groups are used to compare different theories (e.g., Mathieson, 1991), subjects from different groups are exposed to different questions. The presence of directional item context effects can lead to "miscalibration," making it difficult to perform a fair comparison because questions from different theories have change the respondents in different ways. Since the literature has not provided a simple way to deal with directional context effects when comparing competing models, in the following section, we propose a statistical remedy.

\section{A Statistical Remedy for Di- rectional Item Context Effects}

Our review of the literature suggests that there is no simple and effective solution to deal with directional item context effects in theoretical models. For example, Ostroff et al.'s (2002) approach may not be very useful when the research objective is to test a model involving only individual level constructs. In this section, we describe a statistical remedy for directional item context effects and its application using the data collected in Study 2.

The proposed remedy is applicable to experimental data that permit the detection of directional item context effects. Once detected, these effects can be removed from the observed correlations using path analysis. The competing models can then be compared directly. The proposed treatment for directional item context effects is similar to that for extraneous factors described in Hunter 
and Schmidt (2004, p. 117), where an extraneous factor is hypothesized to affect a dependent variable alongside other independent variables. Using path analysis, the effect of the extraneous factor on the dependent variable can be tested.

First of all, we note that every survey creates a context, although some contexts seem to cause more bias than others do. Here, removing directional item context effects actually means removing the directional item context effects relative to some reference context. When two models, each measured by a different survey, are compared, either survey context can be used as the reference. Suppose we decide that TAM2 is the reference model in Study 2. A dummy variable can be created using " 1 " to represent the PMT group and "0" for the TAM2 group ${ }^{4}$. The correlation between the dummy variable and the variable affected by directional item context effects (in this case, INT) is then computed. We denote this variable as $r_{d}$, where the subscript " $d$ " stands for directional item context effects. Based on the data from Study 2, $r_{d}=0.115$ and it is significant at the 0.05 level (2-tailed).

To account for the directional context effects, a path model that includes directional item context effects as a factor is developed, as shown in Figure 4. T-INT refers to the subjects' "true" intention and O-INT refers to the observed intention. The influence of extraneous variables on T-INT is denoted as $e_{\mathrm{T}-\mathrm{INT}}$.

Following the standard approach to path analysis (Cohen et al., 2003) and noting that respondents' T-INT should not be dependent on the experiment group to which they belong, we come up with the following set of simultaneous equations:

\footnotetext{
${ }^{4}$ The analysis results will not be affected if the PMT group is chosen as the reference.
}

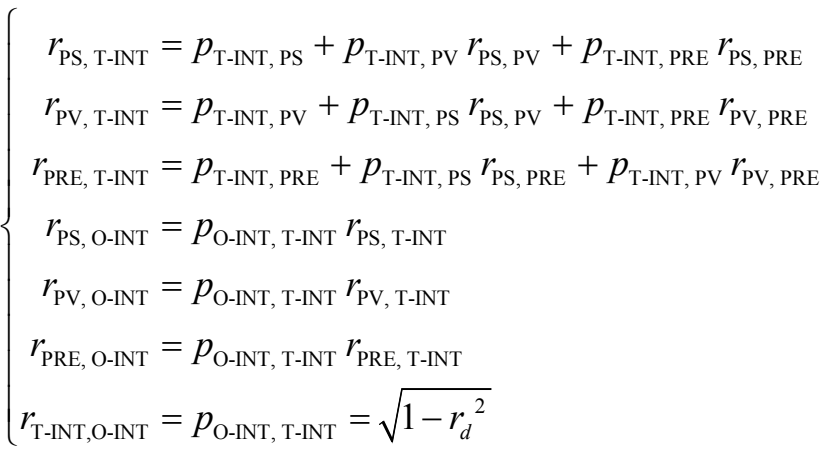

where $r_{x, y}$ denotes the correlation between $x$ and $y$, and $p_{y, x}$ denotes the path coefficient between $x$ and $y$ assuming $x$ causes $y$. Substituting the values of $r_{\mathrm{PS}, \mathrm{PV}}$, $r_{\mathrm{PS}, \mathrm{PRE}}, r_{\mathrm{PV}, \mathrm{PRE}}, r_{\mathrm{PS}, \mathrm{T}-\mathrm{INT}}, r_{\mathrm{PV}, \mathrm{T}-\mathrm{INT}}, r_{\mathrm{PV}, \mathrm{T}-\mathrm{INT}}$, $r_{\mathrm{PV}, \mathrm{O}-\mathrm{INT}}, r_{\mathrm{PRE}, \mathrm{O}-\mathrm{INT}}$ (from Table C2), and $r_{d}$, we can obtain the following path coefficients and correlations: $p_{\mathrm{T}-\mathrm{INT}, \mathrm{PS}}=0.170$, $p_{\mathrm{T}-\mathrm{INT}, \mathrm{PV}}=0.115 \quad, \quad p_{\mathrm{T}-\mathrm{INT}, \mathrm{PRE}}=0.392$, $r_{\mathrm{PS}, \mathrm{T}-\mathrm{INT}}=0.320 \quad, \quad r_{\mathrm{PV}, \mathrm{T}-\mathrm{INT}}=0.162 \quad$, $r_{\mathrm{PRE}, \mathrm{T}-\mathrm{INT}}=0.463$, and $r_{\mathrm{T}-\mathrm{INT}, \mathrm{O}-\mathrm{INT}}=0.993$. The $\mathrm{R}^{2}$ of T-INT is given by

$$
\begin{aligned}
R^{2}=p_{\text {T-INT, PS }} & r_{\text {PS, T-INT }}+p_{\text {T-INT, PV }} r_{\text {PV, T-INT }} \\
& +p_{\text {T-INT, PRE }} r_{\text {PRE,T-INT }}=0.254
\end{aligned}
$$

Because PS, PV, PRE, and O-INT have been standardized in the earlier PLS analysis, the standard errors for $p_{\text {T-INT, PS }}$, $p_{\mathrm{T} \text {-INT, PV }}, p_{\mathrm{T}-\mathrm{INT}, \mathrm{PRE}}$ are, respectively, for $n$ $=171$.

$$
\begin{aligned}
& \frac{1}{r_{\mathrm{T}-\mathrm{INT}, \mathrm{O}-\mathrm{INT}}^{2}} \sqrt{\frac{1-r_{\mathrm{PS}, \mathrm{T}-\mathrm{INT}}^{2}}{n-2}}=0.074 \\
& \frac{1}{r_{\mathrm{T}-\mathrm{INT}, \mathrm{O}-\mathrm{INT}}^{2}} \sqrt{\frac{1-r_{\mathrm{PS}, \mathrm{T}-\mathrm{INT}}^{2}}{n-2}}=0.077 \\
& \frac{1}{r_{\mathrm{T}-\mathrm{INT}, \mathrm{O}-\mathrm{INT}}^{2}} \sqrt{\frac{1-r_{\mathrm{PS}, \mathrm{T}-\mathrm{INT}}^{2}}{n-2}}=0.069
\end{aligned}
$$

Therefore, their $t$-statistics are equal to $2.296,1.495$, and 5.673 and their $p$ values are equal to $0.023,0.137$, and 
Item Context Effects in IS Survey Research / Hui

$5.96 \times 10^{-8}$, respectively. The revised path analysis results are presented in Figure 5. We note that the statistical remedy has not changed the path significances and the $\mathrm{R}^{2}$ dramatically, but the path from PS to INT has now become significant at the 0.05 level. Figure 5 can now be directly compared to Figure $3 a$. Table 4 shows the steps involved in our proposed statistical remedy.

\section{Conclusion}

IS research often seeks to theorize relationships between IT, use of IT and IT productivity. Some of these variables can be operationalized and measured objectively. For these variables, the best way to minimize item context effects is
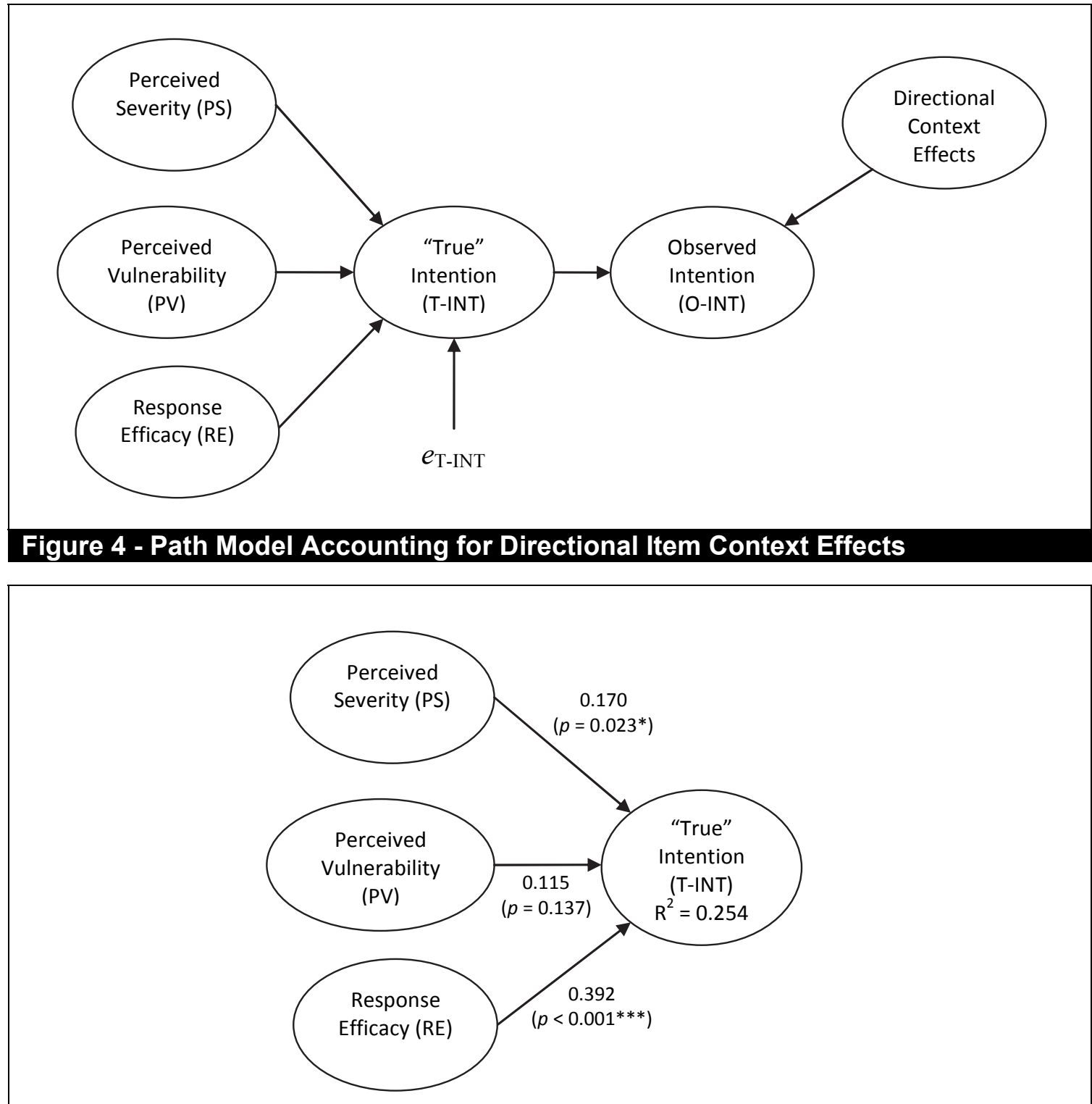

Figure 5 - Path Analysis Results after Accounting for Directional Item Context Effects 
Table 4. Steps involved in The Proposed Statistical Remedy

1. Select the reference model.

2. Create a dummy variable with "0" representing the reference model and "1" representing the other model.

3. Compute $r_{d}$.

4. Break the construct affected by directional context effects into three components: the true value, the observed measurement and directional context effects, i.e., Observed measurement $=$ True value + directional context effects

5. Revise the path model accordingly.

6. Perform path analysis to compute revised path coefficients and $\mathrm{R}^{2}$.

probably to avoid the use of self-reports. However, like other social sciences, there are situations where objective measures are expensive or where the theoretical constructs of interest reside in the mind of the survey respondents (e.g., attitudes and intentions). Then, selfreports may be the best available source of data (Spector, 1987).

This paper contributes to the IS literature by presenting two empirical studies that illustrate the presence of both correlational and directional item context effects in IS survey research. Since it is not always possible to predict whether or not a question item will induce context effects, it is wise for researchers to adopt research design strategies and remedies to minimize or account for these effects before any data collection. We showed that item or construction separation can be used to reduce correlational item context effects without increasing the cognitive burden for survey respondents. We also presented a statistical remedy to correct for directional item context effects in comparative experimental studies.

\section{References}

Bedeian, A. G., Day, D. V. and Kelloway, E. K. (1997). "Correcting for Measurement Error Attenuation in Structural Equation Models: Some Important Reminders," Educational and Psychological Measurement, 57(5), 785-799.

Berman, J. S. and Kenny, D. A. (1976). "Correlational Bias in Observer
The proposed remedy adds statistical complexity to a simple survey study, but the main disadvantage is the need for a reference context group. To eliminate this need, we are currently developing a new technique involving split questionnaire design (Raghunathan and Grizzle, 1995), where different respondents answer only a subset of the question items. Split questionnaire design is often used to reduce survey fatigue in long questionnaires. However, it can also be used to detect possible directional item context effects as a result of exposure to different question items.

An issue that has not been addressed in this study is the relative importance of intraconstruct correlations vs. interconstruct correlations. Sometimes, it is not possible to have separation of question items both within a construct and between constructs. Further work is required to provide guidelines on determining which type of correlational item context effects represents a greater threat to data validity given a research setting.

Ratings," Journal of Personality and Social Psychology, 34 263273.

Bulgurcu, B., Cavusoglu, H. and Benbasat, I. (2010). "Information Security Policy Compliance: An Empirical Study of Rationality-Based Beliefs and Information Security 
Item Context Effects in IS Survey Research / Hui

Awareness," MIS Quarterly, 34(3), 523-548.

Burton-Jones, A. (2009). "Minimizing Method Bias through Programmatic Research," MIS Quarterly, 33(3), 445-471.

Chandon, P., Morwitz, V. G. and Reinartz, W. J. (2005). "Do Intentions Really Predict Behavior? SelfGenerated Validity Effects in Survey Research," Journal of Marketing, 69(2), 1-14.

Cohen, J., Cohen, P., West, S. G. and Aiken, L. S. (2003). Applied Multiple Regression/Correlation Analysis for the Behavioral Sciences ( $3^{\text {rd }}$ Edition), Psychology Press.

Cote, J. A. and Buckley, R. (1987). "Estimating Trait, Method, and Error Variance: Generalizing across 70 Construct Validation Studies," Journal of Marketing Research, 24(3), 579-582.

Crampton, S. M. and Wagner, J. A. (1994). "Percept-percept Inflation in Microorganizational Research: An Investigation of Prevalence and Effects," Journal of Applied Psychology, 79(1), 67-76.

Davis, F. D. (1989). "Perceived Usefulness, Perceivd Ease of Use, and User Acceptance of Information Technology," MIS Quarterly, 13(3), 319-340.

Davis, F. D., Bagozzi, R. P. and Warshaw, P. R. (1989). "User Acceptance of Computer Technology: A Comparison of Two Theoretical Models," Management Science, 35(8), 982-1003.

Davis, F. D. and Venkatesh, V. (1996). "A Critical Assessment of Potential Measurement Biases in the Technology Acceptance Model: Three Experiments," International Journal of Human-Computer Studies, 45(1), 19-45.
DeCoster, J. (2004). "Meta-analysis Notes," retrieved 8 July 2011 from http://www.stathelp.com/notes.html

DeVellis, R. F. (2003). Scale Development: Theory and Application ( $2^{\text {nd }}$ Edition), Sage Publications.

Doty, D. H. and Glick, W. H. (1998). "Common Methods Bias: Does Common Methods Variance Really Bias Results?" Organizational Research Methods, 1(4), 374-406.

Feldman, J. M. and Lynch, J. G. Jr. (1988). "Self-Generated Validity and Other Effects of Measurement on Belief, Attitude, Intention, and Behavior," Journal of Applied Psychology, 73(3), 421-435.

Feldt, L. S. (1969). "A Test of the Hypothesis that Cronbach's Alpha or Kuder-Richardson Coefficient Twenty Is the Same for Two Tests," Psychometrika, 34, 363373.

Fornell, C. and Larcker, D. F. (1981). "Structural Equation Models with Unobservable Variables and Measurement Error: Algebra and Statistics," Journal of Marketing Research, 18(3), 382-388.

Gobet, F. (1998). Expert Memory: A Comparison of Four Theories. Cognition, 66(2), 115-152.

Herath, T. and Rao, H. R. (2009). "Protection Motivation and Deterrence: A Framework for Security Policy Compliance in Organizations," European Journal of Information Systems, 18, 106-125.

Hsiao, T. and Oxford, R. L. (2002). "Comparing Theories of Language Learning Strategies: A Confirmatory Factor Analysis," The Modern Language Journal, 86, 368-383. 
Hunter, J. E. and Schmidt, F. (2004). Methods of Meta-Analysis: Correcting Error and Bias in Research Findings (2nd Edition), Sage, Newbury Park, CA.

King, W. R., Liu, C. Z. and Haney, M. H. (2007). "Method Effects in IS Survey Research: An Assessment and Recommendations," Communications of the Association for Information Systems, 20, 457-482.

Kingston, C. and Caballero, G. (2009). "Comparing Theories of Institutional Change," Journal of Institutional Economics, 5(2), 151-180.

Lynch, J. G., Jr. (2005). "Accessible but Nondiagnostic Memories about Memory and Consumer Choice," in Griffin, A., C. Otnes (eds.). 16th Paul D. Converse Symposium. Chicago: American Marketing Association, 88-115.

Malhotra, N. K., Kim, S. S. and Patil, A. (2006). "Common Method Variance in IS Research: A Comparison of Alternative Approaches and a Reanalysis of Past Research," Management Science, 57(12), 1865-1883.

Mathieson, K. (1991). "Predicting User Intentions: Comparing the Technology Acceptance Model with the Theory of Planned Behavior," Information Systems Research, 2(3), 173-191.

Miller, G. A. (1956). "The Magical Number Seven, Plus or Minus Two: Some Limits on Our Capacity for Processing Information," The Psychological Review, 63, 81-97.

$\mathrm{Ng}$, B.-Y., Kankanhalli, A. and Xu, Y. (2009). 'Studying Users' Computer Security Behavior: A Health Belief Perspective," Decision Support Systems, 46, 815-825.

Nunnally, J. C. (1967). Psychometric Theory. New York: McGraw Hill.
Ostroff, C., Kinicki, A. J. and Clark, M. A. (2002). "Substantive and Operational Issues of Response Bias Across Levels of Analysis: An Example of Climate-Satisfaction Relationships," Journal of Applied Psychology, 87(2), 355-368.

Podsakoff, P. M., MacKenzie, S. B., Lee, J.-Y. and Podsakoff, N. P. (2003). "Common Method Biases in Behavioral Research: A Critical Review of the Literature and Recommended Remedies," Journal of Applied Psychology, 88(5), 879903.

Raghunathan, T. E. and Grizzle, J. E. (1995) "A Split Questionnaire Survey Design," Journal of the American Statistical Association, 90(429), pp. 54-63.

Rogers, R. W. (1975). "A Protection Motivation Theory of Fear Appeals and Attitude Change," Journal of Psychology, 91(1), 93-114.

Rogers, R. W. and Prentice-Dunn, S. (1997). "Protection Motivation Theory," in Gochman, D. S. (ed.). Handbook of Health Behavior Research I: Personal and Social Determinants, Plenum Press, New York.

Sharma, R., Yetton, P. and Crawford, J. (2009). "Estimating the Effect of Common Method Variance: The Method-Method Pair Technique with an Illustration from TAM Research," MIS Quarterly, 33(3), 473-490.

Slovic, P. (1987). "Perception of Risk," Science, 236, 280-285.

Spector, P. E. (1987). "Method Variance as an Artifact in Self-Reported Affect and Perceptions at Work: Myth or Significant Problem?" Journal of Applied Psychology, 72(3), 438-443. 
Item Context Effects in IS Survey Research / Hui

Steiger, J. H. (1980). "Tests for Comparing Elements of a Correlation Matrix," Psychological Bulletin, 87(2), 245-251.

Steiger, J. H. (2003). "Comparing Correlations: Pattern Hypothesis Tests Between and/or Within Independent Samples," In McDonald, R. P., Maydeu-Olivares, A. M., McArdle, J. J. (eds.) Contemporary Psychometrics: A Festschrift for Roderick $P$. McDonald, Routledge.

Taylor, S. and Todd, P. A. (1995). "Understanding Information Technology Usage: A Test of Competing Models," Information Systems Research, 6(2), 144-176.

Tourangeau, R., Rasinski, K. A. and Bradburn, N. (1989a). "Belief Accessibility and Context Effects in Attitude Measurement," Journal of Experimental Social Psychology, 25, 401-421.

Tourangeau, R., Rasinski, K. A., Bradburn, N. and D'andrade, R. (1989b). "Carryover Effects In Attitude Surveys," Public Opinion Quarterly, 53(4), 495-524.
Tourangeau, R. and Rasinski, K. A. (1988). "Cognitive Processes Underlying Context Effects in Attitude Measurement," Psychological Bulletin, 103(3), 299-314.

Tourangeau, R., Rips, L. J. and Rasinski, K. (2000). The Psychology of Survey Response, Cambridge University Press, New York.

Tversky, A. and Kahneman, D. (1974). "Judgments Under Uncertainty: Heuristics and Biases," Science, $185,1124-1131$.

Venkatesh, V. and F. D. Davis (2000). "A Theoretical Extension of the Technology Acceptance Model: Four Longitudinal Field Studies," Management Science ,45(2), 186204.

Wainer, H. and Kiely, G. L. (1987). "Item Clusters and Computerized Adaptive Testing: A Case for Testlets," Journal of Educational Measurement, 24, 185-201. 


\section{Appendix A: Instruments for Constructs of Interest in Study 1}

\begin{tabular}{|c|c|}
\hline Construct & Question Items \\
\hline $\begin{array}{l}\text { Perceived Suscep- } \\
\text { tibility (SUS) }\end{array}$ & $\begin{array}{l}\text { 1. The chances of receiving an email attachment with virus are high. } \\
\text { 2. There is a good possibility that I will receive an email attachment } \\
\text { with virus. } \\
\text { 3. I am likely to receive an email attachment with virus. } \\
\text { 4. It is quite common to receive an email attachment with virus. }{ }^{*}\end{array}$ \\
\hline $\begin{array}{c}\text { Perceived Severity } \\
\text { (SEV) }\end{array}$ & $\begin{array}{l}\text { 1. Having my computer infected by a virus as a result of opening a } \\
\text { suspicious email attachment is a serious problem for me. } \\
\text { 2. Losing data as a result of opening a suspicious email attachment is } \\
\text { a serious problem for me. } \\
\text { 3. If my computer is infected by a virus as a result of opening a suspi- } \\
\text { cious email attachment, my daily work will be negatively affected. } \\
\text { 4. I will be negatively affected if my computer is infected by a virus as } \\
\text { a result of opening a suspicious email attachment. }\end{array}$ \\
\hline $\begin{array}{l}\text { Perceived Benefits } \\
\text { (BEN) }\end{array}$ & $\begin{array}{l}\text { 1. Checking if the sender and subject make sense is effective in pre- } \\
\text { venting viruses from infecting my computer. } \\
\text { 2. Checking if the file name of the email attachment makes sense is } \\
\text { effective in preventing viruses from infecting my computer. } \\
\text { 3. Exercising care before opening email attachments is effective in } \\
\text { preventing viruses from infecting my computer. } \\
\text { 4. Checking if the email message makes sense is effective in prevent- } \\
\text { ing viruses from infecting my computer. }\end{array}$ \\
\hline $\begin{array}{l}\text { Perceived Barriers } \\
\text { (BAR) }\end{array}$ & $\begin{array}{l}\text { 1. Exercising care when reading emails with attachments is inconven- } \\
\text { ient. } \\
\text { 2. Exercising care when reading emails with attachments is time- } \\
\text { consuming. } \\
\text { 3. Exercising care when reading emails with attachments would re- } \\
\text { quire considerable investment of effort other than time. } \\
\text { 4. Exercising care when reading emails with attachments would re- } \\
\text { quire starting a new habit, which is difficult. }\end{array}$ \\
\hline Self-Efficacy (SEF) & $\begin{array}{l}\text { 1. I am confident of recognizing a suspicious email. } \\
\text { 2. I am confident of recognizing suspicious email headers. } \\
\text { 3. I am confident of recognizing suspicious email attachment file } \\
\text { name. } \\
\text { 4. I can recognize a suspicious email attachment even if there was no } \\
\text { one around to help me. }\end{array}$ \\
\hline $\begin{array}{l}\text { General Security } \\
\text { Orientation (GEN) }\end{array}$ & $\begin{array}{l}\text { 1. I read information security bulletins or newsletters. } \\
\text { 2. I am concerned about security incidents and try to take action to } \\
\text { prevent them. } \\
\text { 3. I am interested in information about computer security. } \\
\text { 4. I am constantly mindful about computer security. }\end{array}$ \\
\hline
\end{tabular}

* Item not in the original instrument in $\mathrm{Ng}$ et al. (2009). 
Item Context Effects in IS Survey Research / Hui

\section{Appendix B: Cross-Loadings for Both Experimental Groups in Study 1}

\begin{tabular}{|c|c|c|c|c|c|c|c|c|c|c|c|c|}
\hline & \multicolumn{6}{|c|}{$\begin{array}{c}\text { Group } 1 \\
\text { (No Item Separation) }\end{array}$} & \multicolumn{6}{|c|}{$\begin{array}{c}\text { Group } 2 \\
\text { (Item Separation) }\end{array}$} \\
\hline & BAR & BEN & GEN & SEF & SEV & SUS & BAR & BEN & GEN & SEF & SEV & SUS \\
\hline BAR1 & 0.510 & -0.015 & 0.045 & 0.109 & 0.114 & 0.060 & 0.669 & 0.203 & 0.096 & 0.137 & 0.162 & 0.176 \\
\hline BAR2 & 0.795 & 0.120 & 0.007 & 0.108 & 0.272 & 0.105 & 0.515 & 0.084 & 0.076 & 0.084 & 0.158 & 0.055 \\
\hline BAR3 & 0.796 & 0.115 & 0.103 & 0.095 & 0.143 & 0.109 & 0.716 & 0.235 & 0.154 & 0.147 & 0.329 & 0.101 \\
\hline BAR4 & 0.714 & 0.091 & 0.068 & 0.046 & 0.322 & 0.201 & 0.750 & 0.244 & 0.118 & 0.138 & 0.274 & 0.239 \\
\hline BEN1 & 0.164 & 0.855 & 0.201 & 0.178 & 0.501 & 0.179 & 0.257 & 0.823 & 0.382 & 0.310 & 0.366 & 0.165 \\
\hline BEN2 & 0.174 & 0.822 & 0.107 & 0.116 & 0.407 & 0.062 & 0.234 & 0.765 & 0.315 & 0.343 & 0.280 & 0.265 \\
\hline BEN3 & 0.083 & 0.802 & 0.209 & 0.086 & 0.482 & 0.050 & 0.198 & 0.690 & 0.382 & 0.221 & 0.366 & 0.278 \\
\hline BEN4 & 0.068 & 0.790 & 0.192 & 0.165 & 0.447 & 0.179 & 0.245 & 0.757 & 0.377 & 0.189 & 0.247 & 0.191 \\
\hline GEN1 & 0.090 & 0.125 & 0.630 & 0.269 & -0.028 & 0.187 & -0.001 & 0.193 & 0.480 & 0.306 & 0.132 & 0.155 \\
\hline GEN2 & 0.089 & 0.171 & 0.772 & 0.283 & 0.183 & 0.106 & 0.214 & 0.427 & 0.799 & 0.307 & 0.438 & 0.279 \\
\hline GEN3 & 0.000 & 0.186 & 0.799 & 0.224 & 0.003 & 0.092 & 0.179 & 0.291 & 0.640 & 0.183 & 0.272 & 0.110 \\
\hline GEN4 & 0.060 & 0.174 & 0.783 & 0.234 & 0.015 & 0.102 & 0.019 & 0.340 & 0.750 & 0.383 & 0.240 & 0.081 \\
\hline SEF1 & 0.089 & 0.103 & 0.305 & 0.865 & 0.020 & 0.151 & 0.118 & 0.260 & 0.354 & 0.777 & 0.091 & 0.135 \\
\hline SEF2 & 0.090 & 0.208 & 0.282 & 0.931 & 0.078 & 0.245 & 0.148 & 0.256 & 0.341 & 0.856 & 0.105 & 0.091 \\
\hline SEF3 & 0.114 & 0.132 & 0.258 & 0.884 & 0.031 & 0.201 & 0.233 & 0.388 & 0.366 & 0.896 & 0.207 & 0.089 \\
\hline SEF4 & 0.087 & 0.075 & 0.371 & 0.784 & -0.032 & 0.145 & 0.113 & 0.226 & 0.371 & 0.800 & 0.140 & 0.002 \\
\hline SEV1 & 0.214 & 0.256 & 0.007 & -0.061 & 0.660 & 0.399 & 0.198 & 0.191 & 0.285 & 0.097 & 0.549 & 0.370 \\
\hline SEV2 & 0.230 & 0.328 & 0.019 & 0.056 & 0.735 & 0.333 & 0.093 & 0.179 & 0.287 & 0.123 & 0.443 & 0.294 \\
\hline SEV3 & 0.250 & 0.565 & 0.140 & 0.133 & 0.876 & 0.228 & 0.289 & 0.346 & 0.312 & 0.129 & 0.854 & 0.173 \\
\hline SEV4 & 0.283 & 0.503 & -0.010 & -0.042 & 0.821 & 0.175 & 0.343 & 0.379 & 0.330 & 0.133 & 0.828 & 0.051 \\
\hline SUS1 & 0.154 & 0.141 & 0.168 & 0.253 & 0.284 & 0.848 & 0.262 & 0.222 & 0.237 & 0.060 & 0.158 & 0.868 \\
\hline SUS2 & 0.149 & 0.132 & 0.074 & 0.071 & 0.275 & 0.851 & 0.155 & 0.214 & 0.153 & 0.104 & 0.264 & 0.804 \\
\hline SUS3 & 0.094 & 0.064 & 0.068 & 0.065 & 0.201 & 0.699 & 0.124 & -0.073 & 0.015 & -0.004 & 0.023 & 0.222 \\
\hline SUS4 & 0.144 & 0.104 & 0.168 & 0.309 & 0.261 & 0.781 & 0.162 & -0.024 & 0.124 & 0.094 & 0.126 & 0.328 \\
\hline
\end{tabular}




\section{Appendix C: Instruments for Constructs of Interest in Study 2}

\begin{tabular}{|c|c|c|}
\hline Construct & Answered by & Question Items \\
\hline $\begin{array}{l}\text { Perceived } \\
\text { Ease of Use } \\
\text { (PEOU) }\end{array}$ & Group 1 & $\begin{array}{l}\text { 1. My interaction with Hushmail would be clear and un- } \\
\text { derstandable. } \\
\text { 2. It would be easy for me to become skilful in using } \\
\text { Hushmail. } \\
\text { 3. I would find Hushmail easy to use. }\end{array}$ \\
\hline $\begin{array}{l}\text { Perceived } \\
\text { Usefulness } \\
\text { (PU) }\end{array}$ & Group 1 & $\begin{array}{l}\text { 1. Using Hushmail would benefit me. } \\
\text { 2. Hushmail would be useful to me. } \\
\text { 3. I would find Hushmail useful. }\end{array}$ \\
\hline $\begin{array}{l}\text { Subjective } \\
\text { Norm (SN) }\end{array}$ & Group 1 & $\begin{array}{l}\text { 1. People who influence my behavior would support me } \\
\text { using Hushmail. } \\
\text { 2. People who are important to me would support me us- } \\
\text { ing Hushmail. } \\
\text { 3. People who are important to me would agree that it is } \\
\text { a good idea to use Hushmail. }\end{array}$ \\
\hline $\begin{array}{c}\text { Perceived } \\
\text { Severity (PS) }\end{array}$ & Group 2 & $\begin{array}{l}\text { 1. It is a very offensive invasion of my privacy if other } \\
\text { people can read my personal emails. } \\
\text { 2. I will be very unhappy if other people can read my per- } \\
\text { sonal emails. } \\
\text { 3. I will be very much bothered if other people can read } \\
\text { my personal emails. }\end{array}$ \\
\hline $\begin{array}{l}\text { Perceived } \\
\text { Vulnerability } \\
\text { (PV) }\end{array}$ & Group 2 & $\begin{array}{l}\text { 1. It is likely that some people will try to read my personal } \\
\text { emails without my knowledge. } \\
\text { 2. It is likely that some people will try to gain unauthor- } \\
\text { ized access to my personal emails. } \\
\text { 3. It is likely that some people will try to look into my } \\
\text { emails without my permission. }\end{array}$ \\
\hline $\begin{array}{c}\text { Response } \\
\text { Efficacy (RE) }\end{array}$ & Group 2 & $\begin{array}{l}\text { 1. Hushmail can protect my email privacy. } \\
\text { 2. Hushmail can prevent unauthorized access to my per- } \\
\text { sonal emails. } \\
\text { 3. Hushmail can prevent others from reading my emails } \\
\text { without my knowledge. }\end{array}$ \\
\hline $\begin{array}{l}\text { Intention } \\
\text { (INT) }\end{array}$ & Groups $1 \& 2$ & $\begin{array}{l}\text { 1. I intend to use Hushmail in the future. } \\
\text { 2. I plan to use Hushmail in the future. } \\
\text { 3. I will use Hushmail in the future. }\end{array}$ \\
\hline
\end{tabular}




\section{Appendix D: Construct Validity Analysis for Study 2}

Table C1 presents the Cronbach's alpha values of constructs in both TAM2 and PMT. All of them exceed 0.7 , the threshold for reliability suggested by Nunnally (1967). Table C2 presents the interconstruct correlation matrices generated from SmartPLS 2.0. The AVE of each construct exceeds 0.5 , the benchmark for convergent validity. The square root of the AVE of each construct is greater than the correlations between the construct and other constructs in the model, suggesting adequate discriminant validity (Fornell and Larcker, 1981). Furthermore, the correlations between the dependent and independent variables in both TAM2 and PMT are large and significant, providing evidence of nomological validity.

Table C1 - Cronbach's Alphas of Theoretical Constructs in Each Experimental Group

\begin{tabular}{|l|l|l|l|}
\hline \multicolumn{2}{|c|}{ Group 1 (TAM2) } & \multicolumn{2}{c|}{ Group 2 (PMT) } \\
\hline Perceived Ease of Use (PEOU) & 0.805 & Perceived Severity (PS) & 0.710 \\
\hline Perceived Usefulness (PU) & 0.883 & Perceived Vulnerability (PV) & 0.831 \\
\hline Subjective Norm (SN) & 0.819 & Response Efficacy (RE) & 0.827 \\
\hline Intention (INT) & 0.878 & Intention (INT) & 0.842 \\
\hline
\end{tabular}

\section{Table C2 - Interconstruct Correlation Matrices for Experimental Groups}

\begin{tabular}{|c|l|l|l|l|l|l|l|l|l|}
\hline \multicolumn{5}{|c}{ Group 1 (TAM2) } & \multicolumn{5}{c|}{ Group 2 (PMT) } \\
\hline & EOU & PU & SN & INT & & PS & PV & PRE & INT \\
\hline EOU & 0.847 & & & & PS & 0.798 & & & \\
\hline PU & $0.726^{* * *}$ & 0.900 & & & PV & 0.079 & 0.865 & & \\
\hline SN & $0.682^{* * *}$ & $0.753^{* * *}$ & 0.857 & & PRE & $0.361^{* * *}$ & 0.086 & 0.862 & \\
\hline INT & $0.682^{* * *}$ & $0.839^{* * *}$ & $0.765^{* * *}$ & 0.897 & INT & $0.318^{* * *}$ & $0.161^{*}$ & $0.460^{* * *}$ & 0.871 \\
\hline
\end{tabular}

Note: Diagonal Entries are Average Variance Extracted (AVE) by Constructs.

* Significant at the 0.05 level. ${ }^{* *}$ Significant at the 0.01 level. ${ }^{* * *}$ Significant at the 0.001 level.

\section{About the Authors}

Wendy Hui graduated from Hong Kong University of Science and Technology with a PhD in Information Systems. She has taught in Zayed University and University of Notting- ham Ningbo China. She is currently a senior lecturer at Curtin University. Her current research interests include information security and quantitative research methods. 